\title{
Increasing amounts of dietary myristic acid modify the plasma cholesterol level and hepatic mass of Scavenger receptor BI without affecting bile acid biosynthesis in hamsters**
}

\author{
Carole LOISON ${ }^{\mathrm{a}}$, François MENDY ${ }^{\mathrm{b}}$, Colette SEROUGNE ${ }^{\mathrm{a}}$, \\ Claude LuTTON ${ }^{\mathrm{a} *}$ \\ a Laboratoire de Physiologie de la Nutrition (laboratoire associé à l'INRA), \\ Université Paris-Sud, Centre d'Orsay, bâtiment 447, 91405 Orsay Cedex, France \\ ${ }^{\mathrm{b}}$ Résidence du parc de Béarn, 2 rue du calvaire, 92120 Saint-Cloud, France
}

(Received 6 November 2001; accepted 20 March 2002)

\begin{abstract}
The purpose of this study was to analyze the effects of increasing amounts of dietary myristic acid ( 0.03 to $4.2 \%$ of the total dietary energy) on the plasma and hepatic cholesterol metabolism. Six groups of hamsters received semi-purified diets containing $0.05 \%$ cholesterol and $12.5 \%$ lipids and differing only by the nature of the triglycerides (Safflower oil, lard, lard/coconut oil (1:1), milk fat, milk fat/coconut oil (1:1), coconut oil) for 3 weeks. A positive regression between the plasma cholesterol level and the dietary myristic acid level was observed $(r=0.60, P<0.0001)$. However, it is noteworthy that the increase in plasma total cholesterol only reflects an increase in the level of HDL-cholesterol. In parallel, the mass SR-BI decreased linearly with the increased level of myristic acid in the diet, whereas the LDL-R did not change. This study shows that increasing amounts of myristic acid (0.03 to $4.2 \%)$ do not alter the cholesterol or bile acid metabolism and increase only the HDL-C.
\end{abstract}

myristic acid / cholesterol / LDL receptor / SR-B1 / hamster

Résumé - Des doses croissantes d'acide myristique dans l'alimentation modifient la concentration plasmatique du cholestérol et la quantité de SR-BI, sans affecter la biosynthèse des acides biliaires chez le hamster. Le but de cette étude était d'analyser les effets de doses croissantes d'acide myristique ( 0,03 à 4,2\% de l'apport énergétique total) sur le métabolisme plasmatique et hépatique du cholestérol. Six groupes de hamsters ont reçu des régimes semi-synthétiques contenant $0,05 \%$ de cholestérol et $12,5 \%$ de lipides (carthame, saindoux, saindoux/huile de coco $(1: 1)$,

\footnotetext{
* Correspondence and reprints

E-mail: claude.lutton@ibaic.u-psud.fr

** Supported by a CERIN grant.
} 
matière grasse laitière, matière grasse laitière/huile de coco $(1: 1)$ ou huile de coco) pendant 3 semaines. Une régression positive entre la concentration plasmatique de cholestérol et le pourcentage d'acide myristique du régime a été montrée $(r=0,60, P<0,0001)$. Cependant, cette augmentation plasmatique du cholestérol est uniquement due à celle du HDL-C. En parallèle, la quantité de SR-BI diminue de façon linéaire avec l'augmentation du pourcentage d'acide myristique dans le régime, sans modification de la quantité de récepteurs aux LDL. Cette étude montre que des doses croissantes d'acide myristique ne modifient pas le métabolisme du cholestérol ni celui des acides biliaires chez le hamster et augmente uniquement le HDL-C.

\section{acide myristique / cholestérol / récepteur aux LDL / SR-BI / hamster}

\section{INTRODUCTION}

The role of dietary saturated fatty acids on the plasma level and low-density lipoprotein (LDL) metabolism have been investigated mainly in animals and humans [14, 21, 27, 28, 31]. Amongst saturated fatty acids, myristic acid is generally considered to induce the most important increase in plasma cholesterol, specially in the LDL-cholesterol level $[13,14,46]$. In most of the studies, which led to this conclusion, myristic acid represented a very high percentage of the total dietary energy: $16 \%$ in humans [21] or $16 \%$ [35] to $20 \%$ [46] in hamsters. Moreover, Nicolosi [31] reported that some of the previous animal studies used inadequate dose of dietary cholesterol (either none or too high). Under these conditions (far from physiological doses), myristic acid could alter cholesterol metabolism. Myristic acid seems to be also an important cell component since numerous proteins need to be myristoylated in order to play their biological role in transduction pathways, vesicular trafficking and structural positioning [3]. Myristic acid is found in most mammalian milks. In human milk, it represents $3.4 \%$ of the total energy [17]. All these data suggest that the "ideal" proportion of myristic acid in the dietary lipid part in terms of nutritional benefits still has to be defined.

As noted by Kris-Etherton and Dietschy [20] certain hepatic parameter measures such as the cholesterol and cholesteryl ester concentrations or LDL receptor activity are necessary to understand the effects of dietary fat on plasma cholesterol. Furthermore, the scavenger receptor SR-BI, an HDL receptor [1], plays an important role in plasma cholesterol regulation, specially in rodents [5]. However, only one recent study [39] has reported that saturated fatty acids modify the expression of SR-BI compared to polyunsaturated fatty acids.

Dietary myristic acid could also modulate bile acid biosynthesis, which is the major process of cholesterol degradation in man and animals and can occur through two pathways (neutral and acidic) [44]. Cholesterol $7 \alpha$ hydroxylase (CYP7A1) is the rate-limiting enzyme in the neutral pathway and sterol 27 hydroxylase (CYP27A1) is the rate limiting enzyme in the acidic pathway. Certain studies in other species than the hamster $[4,11]$ reported that dietary saturated fat decreased bile acid biosynthesis.

The aim of this study was to test the hypothesis that myristic acid (0.03 to $4.2 \%)$ has no undesirable effects on plasma cholesterol (particularly an increase in the LDL fraction). The effects of dietary myristic acid on the lipid concentrations, masses of lipoprotein receptors (LDLr, SR-BI) and activities of certain key enzymes of cholesterol and bile acid metabolism (HMGCoA R, CYP7A1, CYP27A1) in the liver were also observed. For that purpose, hamsters received diets with low concentrations of cholesterol $(0.05 \%)$ and a lipid content $(12.5 \%)$, which represented $27 \%$ of the total dietary energy (i.e. generally advised for 
human nutrition by Grundy [9]). Under these nutritional conditions, myristic acid varies between 0.03 to $4.2 \%$ of the total dietary energy (i.e. close to that found in mammalian milks). The hamster is an animal model which has a well-established similarity with human cholesterol metabolism [37] and is sensitive to changes in the composition of dietary fats $[20,25,38]$.

\section{MATERIALS AND METHODS}

\subsection{Chemicals and isotopes}

Kits for cholesterol, triglyceride and phospholipid assays were purchased from Boehringer-Mannheim (Meylan, France) (CHOD-PAP and GPO-PAP methods), and from Wako Unipath (Dardilly, France). P. Roach (Adelaide, Australia) kindly provided a polyclonal antibody raised against the LDL receptor purified from bovine adrenal cortex. An antibody against a peptide containing residues 495-509 from murine SR-BI was used to detect SR-BI (kindly prepared by André Mazur, Theix, France) [1]. Hydroxymethylglutaryl coenzyme A, $\left[5-{ }^{3} \mathrm{H}\right]$ mevalonolactone, $\left[4-{ }^{14} \mathrm{C}\right]$ cholesterol and $\left[24-{ }^{14} \mathrm{C}\right]$ chenodeoxycholic acid were obtained from Dupont-NEN Products (Les Ulis, France). Emulsifier-safe was purchased from Packard Instrument Company (Meriden, CT, USA). Hydroxypropyl$\beta$-cyclodextrin was kindly provided by Société Roquette frères (62 136 Lestrem, France).

\subsection{Experimental design}

Weanling male golden Syrian Hamsters (Mesocritus Auratus) from our breeding unit designated LPN (Laboratoire de Physiologie de la Nutrition) were fed a standard diet (which contained 5\% lipids) for 2 weeks in order to homogenize their body weight before the experiment. At 5 weeks of age, they were randomly assigned to one of the following six semi-synthetic dietary groups (Tab. I). The basal composition of these diets ( $\mathrm{g} \cdot 100 \mathrm{~g}^{-1}$ of total dry weight) was as

Table I. Fatty acid composition of the test diets.

\begin{tabular}{|c|c|c|c|c|c|c|}
\hline Fatty acids & SA & LA & $\begin{array}{c}\mathrm{LCO} \\
\mathrm{g} \cdot 100 \mathrm{~g}^{-1} \text { of total }\end{array}$ & $\begin{array}{c}\text { MI } \\
\text { fatty acids }\end{array}$ & $\mathrm{MCO}$ & $\mathrm{CO}$ \\
\hline$<12: 0$ & 0 & $0.06(0.02)^{1}$ & $5.5(1.5)$ & $4.1(1.1)$ & $7.5(2.1)$ & 10.9 \\
\hline $12: 0$ & 0 & $0.1 \quad(0.03)$ & $18.3(5.1)$ & $3.7(1.0)$ & $20.1(5.6)$ & $36.6(10.1)$ \\
\hline 14:0 & $0.1(0.03)$ & $1.8(0.5)$ & $8.4(2.3)$ & $10.3(2.8)$ & $12.6(3.5)$ & $(4.2)$ \\
\hline $16: 0$ & $6.6(1.8)$ & 21.6 & $15.2(4.2)$ & $26.9(7.5)$ & $17.8(4.9)$ & $8.77(2.4)$ \\
\hline 18:0 & $2.8(0.8)$ & $14 \quad(3.9)$ & $8.4(2.3)$ & $9.1(2.5)$ & $6 \quad(1.7)$ & $2.86(0.8)$ \\
\hline $18: 1 n-9$ & $22.7(6.3)$ & 46.4 (12.9) & $33.0(9.2)$ & $32.5(9)$ & $26.1(7.2)$ & $19.6 \quad(5.4)$ \\
\hline $18: 2 n-6$ & $64.6(17.9)$ & $10.2(2.8)$ & $7.5(2.1)$ & $5.3(1.5)$ & $5.0(1.4)$ & $4.81(1.3)$ \\
\hline $18: 3 n-3$ & $0.9(0.3)$ & $1.4(0.4)$ & 1.1( & $1.3(0.4)$ & $1.1(0.3)$ & $0.8(0.24)$ \\
\hline SFA & $10.3(2.9)$ & 38.7 (10.7) & $56.5(15.7)$ & $57.8(16)$ & $66 \quad(18.3)$ & $74.3 \quad$ (20.6) \\
\hline MUFA & $23.3(6.5)$ & 49.6 (13.8) & 34.7 (9.6) & $35.6(9.9)$ & 27.7 (7.7) & $19.8(5.5)$ \\
\hline PUFA & $65.5(18.2)$ & $11.6 \quad(3.2)$ & $8.7(2.4)$ & $6.5(1.8)$ & $6.2(1.7)$ & 5.7 (1.6) \\
\hline $\mathrm{P} / \mathrm{S}$ & 6.3 & 0.3 & 0.1 & 0.1 & 0.09 & 0.08 \\
\hline
\end{tabular}

\footnotetext{
${ }^{1}$ Values in parentheses represent percent energy contributed by the individual fatty acid.

SA: $10 \%$ safflower oil $+2.5 \%$ rape/oleisol oil mix $(1: 1)$, LA: $10 \%$ lard $+2.5 \%$ rape/oleisol oil mix $(1: 1)$, LCO $5 \%$ lard $+5 \%$ coconut oil $+2.5 \%$ rape/oleisol oil mix $(1: 1)$, MI: $10 \%$ milk fat $+2.5 \%$ rape/oleisol oil mix $(1: 1)$, MCO: $5 \%$ milk fat $+5 \%$ coconut oil $+2.5 \%$ rape/oleisol oil mix (1:1), CO: $10 \%$ coconut oil $+2.5 \%$ rape/oleisol oil mix (1:1). SFA: saturated fatty acids, MUFA: monounsaturated fatty acids, PUFA: polyunsaturated fatty acids. P/S: ratio of polyunsaturated fatty acids to saturated fatty acids.
} 
follows: 34.95 corn starch, 20 sucrose, 20 casein, 2.5 vitamin mix $^{\mathrm{a}}, 5$ mineral mix ${ }^{\mathrm{b}}$, 5 cellulose, 0.05 cholesterol, 12.5 lipid (10 natural fat +2.5 rape/oleisol mix $(1 / 1)$ which brought the minimum essential fatty acids. The six diet groups differed only in their natural fat component: SA (safflower), LA (lard), LCO (lard + coconut), MI (milk fat), MCO (milk fat + coconut) or $\mathrm{CO}$ (coconut) in order to vary the percentage of myristic acid (14:0) in the diet from 0.03 to $4.2 \%$ of the total dietary energy (Tab. I). Six groups of 13 or 14 hamsters were fed with the six different diets for 3 weeks (duration of feeding usually used in our laboratory).

a Vitamin mix prepared on cellulose support (per kg of diet): Retinyl acetate, 50000 IU; ergocalciferol, 6250 IU; thiamin, $50 \mathrm{mg}$; riboflavin, $37.5 \mathrm{mg}$; calcium pantothenate, $175 \mathrm{mg}$; pyridoxine, $25 \mathrm{mg}$; mesoinositol, $375 \mathrm{mg}$; vitamin B12, $0.125 \mathrm{mg}$; vitamin C, $2000 \mathrm{mg}$; DL $\alpha$ tocopherol, $425 \mathrm{mg}$; menadione, $100 \mathrm{mg}$; nicotinic acid, $250 \mathrm{mg}$; choline, $3400 \mathrm{mg}$; folic acid, $12.5 \mathrm{mg}$; biotin $0.75 \mathrm{mg}$; para-amino benzoic acid, $125 \mathrm{mg}$; cellulose $17.37 \mathrm{mg}$.

${ }^{\mathrm{b}}$ Mineral mix (g per kg of diet): $\mathrm{NaCl}, 5$; $\mathrm{KCl}, 5 ; \mathrm{CaHPO}_{4}, 21.5 ; \mathrm{Mg} \mathrm{Cl}_{2}, 2.5 ; \mathrm{MgSO}_{4}$, 2.5; $\mathrm{Fe}_{2} \mathrm{O}_{3}, 0.15 ; \mathrm{FeSO}_{4}, 7 \mathrm{H}_{2} \mathrm{O}, 0.25$; $\mathrm{MnSO}_{4}, \mathrm{H}_{2} \mathrm{O}, 0.1225 ; \mathrm{CuSO}_{4}, 5 \mathrm{H}_{2} \mathrm{O}, 0.025$; $\mathrm{ZnSO}_{4}, 7 \mathrm{H}_{2} \mathrm{O}, 0.1004 ; \mathrm{CoSO}_{4}, 7 \mathrm{H}_{2} \mathrm{O}$, 0.0002; KI, 0.0004, Corn Starch, 12.851.

The hamsters were individually caged and had free access to food and water. Lighting conditions were controlled according to a $12 \mathrm{~h}$ light-12 h dark cycle ( $7 \mathrm{am}-7 \mathrm{pm})$. The temperature was maintained at $25^{\circ} \mathrm{C}$.

The standard diet, vitamin mix and mineral mix were purchased from UAR (Villemoisson, 91360 Epinay/Orge, France); lard (Orsay, France); safflower oil was given by LESIEUR; coconut oil and milk fat "huile de beurre corman" were given by NUTRINOV (35000 Rennes, France). All the experiments were conducted according to French Regulations for Animal Experi- mentation (Art 19, Oct 1987, Ministry of Agriculture).

After weaning, the animals were fed a standard diet (which contained 5\% lipids) for 2 weeks in order to homogenize their body weight before the experiment. Six groups of 13 or 14 hamsters were fed with the six different diets for 3 weeks (duration of feeding usually used in our laboratory). At the end of the experimental period, the animals were anaesthetized with an intramuscular injection of Tiletamine and Zolazepam (Zoletil 50, Virbac, Carros, France) at a dose of $100 \mathrm{mg} \cdot \mathrm{kg}^{-1}$ body weight and sacrificed by heart blood puncture on heparin. Plasma was separated from blood cells by centrifugation $\left(10 \mathrm{~min}\right.$ at $2600 \mathrm{~g}$, at $4{ }^{\circ} \mathrm{C}$ ) and stored at $-20{ }^{\circ} \mathrm{C}$ for further analysis. The abdomen was opened by a midline incision and the liver was excised, weighed and aliquots were taken for lipid measurement, LDL and SR-BI receptor masses and enzymatic assays.

\subsection{Plasma and lipoproteins}

Plasma lipids were measured by enzymatic procedures using commercial kits. Lipoproteins were fractionated by ultracentrifugation of $2 \mathrm{~mL}$ plasma samples (plasma of 6 hamsters per group were pooled, $n=1$ ) in a density gradient [43], using a SW41 rotor in an L8-70 apparatus (Beckman instruments, Gagny, France). On the basis of the cholesterol content in the gradient, the level and composition of the major lipoprotein classes, i.e., very low density lipoproteins and chylomicrons (VLDL + chylomicrons, $d<1.010$ ), low density lipoproteins (LDL, $1.010 \leq d<1.063$ ), and high density lipoproteins (HDL, $1.063 \leq d \leq 1.20$ ), were determined from the sum of the appropriate fractions, according to their density.

\subsection{Liver lipids}

Frozen liver samples $(0.5 \mathrm{~g})$ were thawed and homogenized in $5 \mathrm{~mL}$ isopropanol, 
using an Ultra-Turrax apparatus (Janke \& Kunkel Gmb \& Co., Staufen, Germany). After incubation at $60^{\circ} \mathrm{C}$ for $1 \mathrm{~h}$ and centrifugation for $5 \mathrm{~min}$ at $3000 \mathrm{~g}$, the supernatant was collected and the pellet was re-extracted with $5 \mathrm{~mL}$ isopropanol. Triglycerides and total cholesterol were measured enzymatically on pooled isopropanolic extracts, using appropriate kits. Free and esterified cholesterol were separated by thinlayer chromatography on silica gel plates eluted with diethyl ether, dried and dissolved in isopropanol prior to enzymatic cholesterol determination.

\subsection{Hepatic enzyme activities}

Microsomal and mitochondrial fractions were isolated according to the procedure described by Einarsson et al. [7] and Souidi et al. [41]. HMGCoA reductase activity was determined in the microsomal fractions, in the presence of alkaline phosphatase using Phillip and Shapiro's radioisotopic technique [32]. CYP7A1 was assayed in the microsomal fractions according to a radioisotopic method using $\left[4-{ }^{14} \mathrm{C}\right]$ cholesterol, solubilized and carried by hydroxypropyl- $\beta$-cyclodextrin [40]. CYP27A1 was assayed in the mitochondrial fractions according to a radioisotopic method using [4- $\left.{ }^{14} \mathrm{C}\right]$ cholesterol, solubilized and carried by hydroxypropyl- $\beta$-cyclodextrin [41].

\section{6. $\mathrm{LDL}$ and SR-BI receptor binding}

Total membranes from frozen liver samples stored at $-80{ }^{\circ} \mathrm{C}(1 \mathrm{~g})$ were prepared according to Kovanen et al. [19]. Membrane proteins were solubilized in a buffer containing Triton-X100 2\% [36]. They were then assayed by Lowry's method [26] using bovine serum albumin as a standard.

Immunodetection was then carried out for the LDL-receptor and scavenger receptor class B, Type I (SR-BI). Liver protein membranes were diluted in a dilution buffer
(Tris-maleate, $125 \mathrm{mM}$; $\mathrm{CaCl}_{2}, 2 \mathrm{mM}$, $200 \mathrm{IU} \cdot \mathrm{mL}^{-1}$ aprotinin; $\mathrm{pH}$ 6). $15 \mathrm{mM}$ of DTT were added to the buffer for the SR-BI only. Diluted samples ( $2 \mu \mathrm{g}$ in $50 \mu \mathrm{L})$ used for the SR-BI immunodetection (not for LDL immunodetection) were boiled $5 \mathrm{~min}$ at $90{ }^{\circ} \mathrm{C}$ before use. Samples were spotted onto a nitrocellulose membrane using a dotblot apparatus (Bio-Rad, Richmond, CA). The nitrocellulose membranes were incubated in quenching buffer containing 5\% fat-free milk (Tris- $\mathrm{HCl}, 25 \mathrm{mM}$; $\mathrm{NaCl}$, $\left.25 \mathrm{mM} ; \mathrm{CaCl}_{2} 2 \mathrm{mM}, \mathrm{pH} 8\right)$. The membranes were washed with TTBS $(\mathrm{NaCl}$, $500 \mathrm{mM}$; Tris-base, 250mM; Tween 20, $0.05 \%, \mathrm{pH} 7.5)$ buffer and incubated for $1 \mathrm{~h} 30$ in the presence of the primary antibody, diluted 1:2000 in an incubation buffer containing $0.1 \%$ fat-free milk (Tris-HCL, $60 \mathrm{mM}$; NaCl, $25 \mathrm{mM} ; \mathrm{CaCl}_{2}, 2 \mathrm{mM}, \mathrm{pH} 8$ ). The membranes were washed three times with TTBS and incubated for $1 \mathrm{~h} 30$ with anti-immunoglobulin antibodies conjugated with horseradish peroxidase at 1:5000 for the LDL-receptor or 1:2000 for the SR-BI receptor. The membranes were washed three times with TTBS buffer, and incubated for 1 min with a chemiluminescence reagent (ECL, Amersham). The sensitive film was revealed in a dark room and the intensity of the spots was measured with a laser densitometer (ultroscan 2222 LKB, Sweden). The relative SR-BI or LDL-receptor content in each spot was estimated by the peak height of the scan.

The linearity of the response as a function of the protein quantity spotted was checked. The specific antibodies raised against the LDL-receptor and SR-BI gave a unique band in western blots with apparent molecular weights of about 130 and $82 \mathrm{kD}$ respectively [29].

\subsection{Statistical analysis}

Results were given as mean values and their SEM. Statistical differences among the groups were determined by ANOVA 
analysis and the Student Newman-Keuls test. A value of $p<0.05$ was considered significant. Multiple regression analyses were performed using the statistical software package statview 4.5 for windows. A regression with a value of $p<0.05$ was considered significant.

\section{RESULTS}

\subsection{Physiological status}

All the animals were in good health after the 3-week experimental diet period. Weight gains during the experimental period were similar whatever the diet ( $24 \pm 1 \mathrm{~g})$. Consumption during the experimental period was the same in each group $\left(6.1 \pm 0.4 \mathrm{~g} \cdot \mathrm{day}^{-1}\right)$.

\subsection{Plasma lipid concentrations and lipoprotein}

Plasma lipid concentrations are shown in Table II. Plasma cholesterol levels remained low in the SA and LA groups compared to the other groups. Multiple regression analyses were used in order to sort out the relative contribution of each fatty acid to the plasma cholesterol concentration. The data are shown in Table III. Positive regressions between the plasma cholesterol concentration and total saturated fat as well as short chain fatty acids $(<12: 0)$, lauric acid (12:0), myristic acid (14:0) or palmitic acid (16:0) were established.

Negative regressions between the plasma cholesterol concentration and total polyunsaturated fatty acids as well as linoleic acid (18:2n-6) were also observed. Among the fatty acids, the strongest regression was obtained with myristic acid.

Plasma phospholipid concentrations were lower in the SA group than in the other groups. There was no significant difference in the triglyceride concentrations between the different groups.

The distribution of plasma cholesterol in the lipoprotein fractions for each group is illustrated in Figure 1. A small increase in LDL-cholesterol was observed only in the LCO group. HDL cholesterol decreased by $20 \%$ in animals fed the SA and LA diets. There was no other noticeable difference in the composition (triglyceride, phospholipid or protein) of the lipoproteins in the different groups (data not shown).

\subsection{Hepatic lipid concentrations}

The hepatic free, ester, and total cholesterol concentrations are shown in Table IV. The free cholesterol concentration remained the same in all the groups. Higher values of total cholesterol and cholesteryl ester were

Table II. Plasma lipid concentrations from hamsters fed semi-purified diets containing different dietary fatty acids: SA (safflower oil), LA (lard), LCO (lard and coconut oil (1:1)), MI (milk fat), MCO (milk and coconut (1:1)), CO (coconut oil) ${ }^{1}$.

\begin{tabular}{lcccccc}
\hline & $\mathrm{SA}(n=14)$ & $\mathrm{LA}(n=13)$ & $\mathrm{LCO}(n=13)$ & $\mathrm{MI}(n=14)$ & $\mathrm{MCO}(n=13)$ & $\mathrm{CO}(n=13)$ \\
\cline { 2 - 6 } & \multicolumn{5}{c}{$\mathrm{mg} \cdot \mathrm{dL}^{-1}$} \\
\hline Cholesterol & $146 \pm 7^{\mathrm{a}}$ & $151 \pm 5^{\mathrm{a}}$ & $197 \pm 6^{\mathrm{b}}$ & $194 \pm 9^{\mathrm{b}}$ & $203 \pm 6^{\mathrm{b}}$ & $186 \pm 6^{\mathrm{b}}$ \\
Phospholipids & $246 \pm 11^{\mathrm{a}}$ & $283 \pm 9^{\mathrm{b}}$ & $302 \pm 9^{\mathrm{b}}$ & $308 \pm 6^{\mathrm{b}}$ & $321 \pm 7^{\mathrm{b}}$ & $332 \pm 9^{\mathrm{b}}$ \\
Triglycerides & $133 \pm 17$ & $162 \pm 14$ & $149 \pm 14$ & $162 \pm 11$ & $191 \pm 27$ & $206 \pm 25$
\end{tabular}

\footnotetext{
${ }^{1}$ Results are expressed as mean $\pm \mathrm{SEM}, n$, number of hamsters per group. Values in each line without a common superscript are significantly different as determined by ANOVA followed by a Student-Newman-Keuls test $(P<0.05)$.
} 


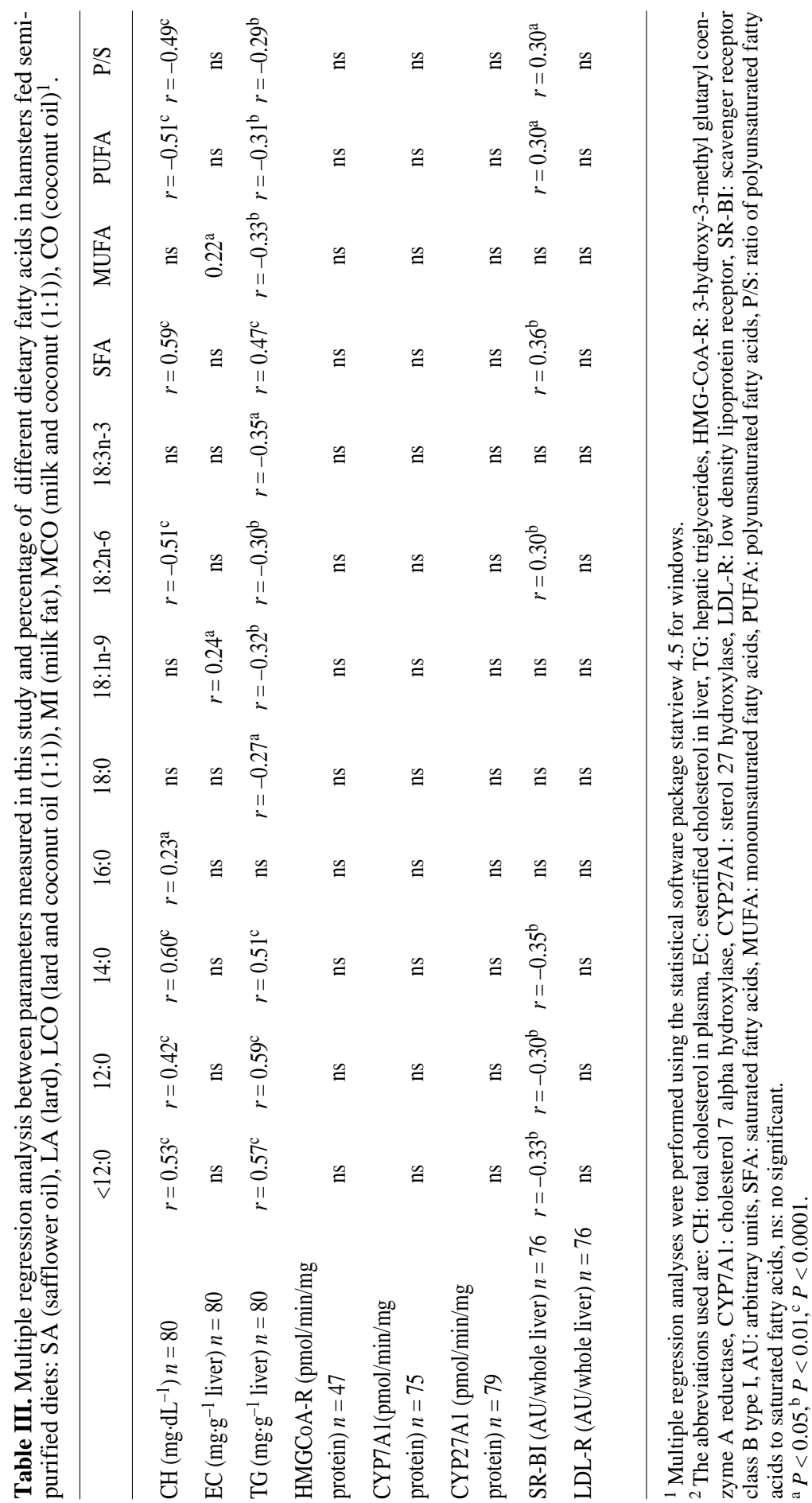


observed in the LCO group compared to the SA, MI and CO groups. No significant regressions (Tab. III) can be established between the hepatic cholesteryl ester
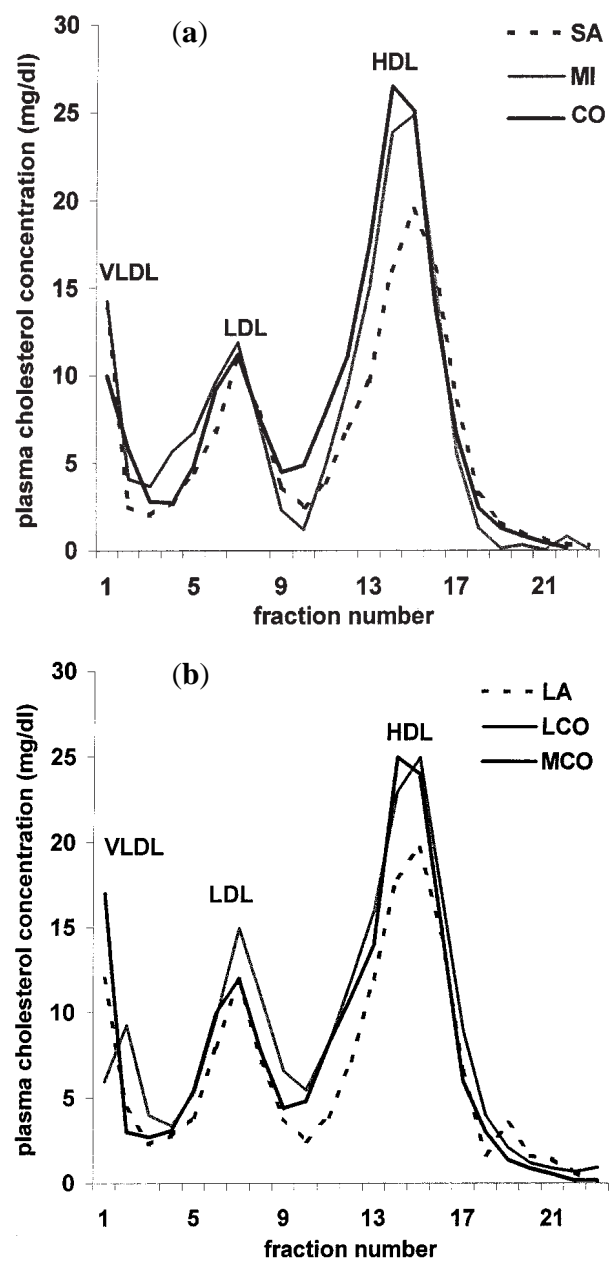

Figure 1. (a) Distribution of plasma cholesterol in lipoprotein fractions separated by density-gradient ultracentrifugation from plasma samples collected in animals fed SA: safflower oil or MI: milk fat or CO: coconut oil. (b) Distribution of plasma cholesterol in lipoprotein fractions separated by density-gradient ultracentrifugation from plasma samples collected in animals fed LA: lard or LCO: lard and coconut oil or MCO: milk fat and coconut oil. Plasma of 6 hamsters per group $(n=1)$ were pooled before separating the lipoprotein fractions. concentration and the percentage of individual saturated fatty acid in the diet. However, regressions between the hepatic cholesteryl ester concentration and total unsaturated fat as well as oleic acid were observed.

A significant decrease in the liver triglyceride concentration was seen after feeding the MI, LA and SA diets while phospholipid concentrations were lower in the LA and MI groups only. Positive regressions (Tab. III) between the hepatic triglyceride concentration and total saturated fat as well as short chain, lauric or myristic acids were observed. Negative regressions between the hepatic triglyceride concentration and total unsaturated or polyunsaturated fat, as well as stearic, oleic, linoleic or linolenic acids were also observed. Among the fatty acids, the strongest regression was obtained with lauric acid.

\subsection{Hepatic enzyme activities}

No significant differences in the hepatic enzyme activities (HMGCoA-R, CYP7A1 and CYP27A1) were found in the six groups (Tab. V). There were no significant regressions between the hepatic enzyme activities and the percentage of individual fatty acids in the diet (Tab. III).

\subsection{Hepatic LDL and SR-BI masses}

The LDL and SR-BI receptor masses in hamsters fed different diets are shown in Table VI. The LDL-receptor mass was higher in the LCO group than in the MCO group. There was no significant difference in the other groups.

The SR-BI mass increased in the SA group compared to the $\mathrm{CO}, \mathrm{LCO}$ and $\mathrm{MI}$ groups. The SR-BI mass increased significantly in the LA group compared to the $\mathrm{CO}$ and LCO groups.

Multiple regression analyses were used in order to sort out the relative contribution of 
Table IV. Hepatic lipid contents from hamsters fed semi-purified diets containing different dietary fatty acids: SA (safflower oil), LA (lard), LCO (lard and coconut oil (1:1)), MI (milk fat), MCO (milk and coconut (1:1)), $\mathrm{CO}$ (coconut oil) ${ }^{1}$.

\begin{tabular}{lcccccc}
\hline & SA $(n=14)$ & LA $(n=13)$ & LCO $(n=13)$ & MI $(n=14)$ & MCO $(n=13)$ & CO $(n=13)$ \\
\cline { 2 - 7 } & \multicolumn{7}{c}{$\mathrm{mg} \cdot \mathrm{g}^{-1}$ liver } \\
\hline TC $^{2}$ & $6.39 \pm 0.69^{\mathrm{a}}$ & $7.52 \pm 1.24^{\mathrm{a}, \mathrm{b}}$ & $10.14 \pm 0.70^{\mathrm{b}}$ & $5.59 \pm 0.78^{\mathrm{a}}$ & $7.63 \pm 1.03^{\mathrm{a}, \mathrm{b}}$ & $4.31 \pm 0.67^{\mathrm{a}}$ \\
$\mathrm{FC}$ & $1.90 \pm 0.10$ & $1.88 \pm 0.07$ & $1.80 \pm 0.07$ & $1.69 \pm 0.08$ & $1.59 \pm 0.06$ & $1.78 \pm 0.06$ \\
$\mathrm{EC}$ & $4.49 \pm 0.66^{\mathrm{a}, \mathrm{b}}$ & $5.64 \pm 1.21^{\mathrm{a}, \mathrm{b}, \mathrm{c}}$ & $8.34 \pm 0.68^{\mathrm{c}}$ & $3.90 \pm 0.75^{\mathrm{a}, \mathrm{b}}$ & $6.04 \pm 0.98^{\mathrm{b}, \mathrm{c}}$ & $2.52 \pm 0.62^{\mathrm{a}}$ \\
TG & $9.43 \pm 0.42^{\mathrm{a}}$ & $8.94 \pm 0.68^{\mathrm{a}}$ & $12.91 \pm 0.88^{\mathrm{b}}$ & $9.88 \pm 0.57^{\mathrm{a}}$ & $12.67 \pm 0.46^{\mathrm{b}}$ & $13.38 \pm 0.84^{\mathrm{b}}$ \\
PL & $15.69 \pm 0.34^{\mathrm{b}, \mathrm{c}}$ & $13.27 \pm 0.26^{\mathrm{a}}$ & $14.64 \pm 0.31^{\mathrm{b}}$ & $13.37 \pm 0.27^{\mathrm{a}}$ & $15.40 \pm 0.36^{\mathrm{b}, \mathrm{c}}$ & $16.33 \pm 0.42^{\mathrm{c}}$ \\
\end{tabular}

${ }^{1}$ Results are expressed as mean \pm SEM, $n$, number of hamsters per group. Values in each line without a common superscript are significantly different as determined by ANOVA followed by a Student-Newman-Keuls test $(P<0.05)$.

2 The abbreviations used are TC: total cholesterol, FC: free cholesterol, EC: esterified cholesterol, TG: triglycerides, PL: phospholipids.

Table V. Hepatic enzymes activities from hamsters fed semi-purified diets containing different dietary fatty acids: SA (safflower oil), LA (lard), LCO (lard and coconut oil (1:1)), MI (milk fat), MCO (milk and coconut (1:1)), $\mathrm{CO}$ (coconut oil) ${ }^{1}$.

\begin{tabular}{lcccccc}
\hline & SA & LA & LCO & MI & MCO & CO \\
\cline { 2 - 7 } & \multicolumn{7}{c}{$\mathrm{pmol} / \mathrm{min} / \mathrm{mg}$ protein } \\
\hline HMGCoA-R ${ }^{2}$ & $13.0 \pm 2.3$ & $20.5 \pm 5.3$ & $23.8 \pm 5.2$ & $21.2 \pm 9.1$ & $15.4 \pm 2.8$ & $27.5 \pm 10.2$ \\
& $n=8$ & $n=7$ & $n=7$ & $n=7$ & $n=10$ & $n=8$ \\
CYP7A1 & $22.8 \pm 1.7$ & $22.1 \pm 3.3$ & $20.7 \pm 1.3$ & $21.9 \pm 1.6$ & $21.4 \pm 1.5$ & $20.8 \pm 2.9$ \\
& $n=14$ & $n=9$ & $n=12$ & $n=14$ & $n=13$ & $n=13$ \\
CYP27A1 & $56.0 \pm 7.3$ & $47.0 \pm 4.6$ & $55.0 \pm 4.5$ & $49.5 \pm 3.7$ & $57.0 \pm 4.3$ & $48.0 \pm 4.5$ \\
& $n=14$ & $n=13$ & $n=13$ & $n=14$ & $n=12$ & $n=13$ \\
\hline
\end{tabular}

${ }^{1}$ Results are expressed as mean \pm SEM, $n$, number of hamsters per group.

2 The abbreviations used are HMG-CoA-R: 3-hydroxy-3-methyl glutaryl coenzyme A reductase, CYP7A1: cholesterol 7 alpha hydroxylase, CYP27A1: sterol 27 hydroxylase.

Table VI. LDL and SR-BI receptor masses from hamsters fed semi- purified diets containing different dietary fatty acids: SA (safflower oil), LA (lard), LCO (lard and coconut oil (1:1)), MI (milk fat), MCO (milk and coconut (1:1)), $\mathrm{CO}$ (coconut oil) ${ }^{1}$.

\begin{tabular}{lcrcccc}
\hline & SA $(n=13)$ & LA $(n=13)$ & LCO $(n=13)$ & MI $(n=13)$ & MCO $(n=12)$ & CO $(n=12)$ \\
\cline { 2 - 6 } & \multicolumn{5}{c}{ AU $\cdot w_{h o l e}^{-1}$ liver } \\
\hline LDL r & $894 \pm 122^{\mathrm{a}, \mathrm{b}}$ & $1040 \pm 159^{\mathrm{a}, \mathrm{b}}$ & $1470 \pm 199^{\mathrm{b}}$ & $1276 \pm 151^{\mathrm{a}, \mathrm{b}}$ & $819 \pm 122^{\mathrm{a}}$ & $1228 \pm 142^{\mathrm{a}, \mathrm{b}}$ \\
SR-BI & $847 \pm 103^{\mathrm{c}}$ & $813 \pm 116^{\mathrm{b}, \mathrm{c}}$ & $398 \pm 40^{\mathrm{a}}$ & $504 \pm 53^{\mathrm{a}, \mathrm{b}}$ & $726 \pm 129^{\mathrm{a}, \mathrm{b}, \mathrm{c}}$ & $462 \pm 87^{\mathrm{a}}$ \\
\hline
\end{tabular}

${ }^{1}$ Results are expressed as mean \pm SEM, $n$, number of hamsters per group. Values in each line without a common superscript are significantly different as determined by ANOVA followed by a Student-Newman-Keuls test $(P<0.05)$

2 The abbreviations used are: LDL r: low density lipoprotein receptor, SR-BI: scavenger receptor class B type I, AU: arbitrary units. 
each fatty acid to the SR-BI mass (Tab. III). Positive regressions between the SR-BI mass and total polyunsaturated fat as well as linoleic acid were observed. Negative regressions between the SR-BI mass and total saturated fat as well as short chain, lauric or myristic acids were also observed. Among the fatty acids the strongest regression was observed with myristic acid.

\section{DISCUSSION}

This study was specifically designed to see if myristic acid (14:0), a natural component of mammalian milk, really produces negative effects on cholesterol metabolism as usually reported in the literature, when investigated at "more realistic" doses $(0.03$ to $4.2 \%$ of the total dietary energy). The results indicate that hamsters fed $\mathrm{CO}, \mathrm{MCO}$, MI and LCO diets (higher in myristic acid) have a total plasma cholesterol concentration higher (+20\%) than those fed LA and SA diets (lower in myristic acid). In the present study, it was technically impossible to strictly control the variations in the ratio of polyunsaturated/saturated fatty acids (P:S) (Tab. I). Therefore, it may be difficult to discriminate whether the increase in cholesterolemia is due to variations in the myristic acid proportions and/or to variations in the P:S ratio. Nevertheless, a previous study [12] has shown that there is no significant difference in the total plasma cholesterol between rhesus monkey fed diets with a similar percentage of myristic acid but with a different $\mathrm{P} / \mathrm{S}$ ratio. Moreover, in the present study, multiple regression analysis (Tab. III) shows that the regression between total cholesterol and the percentage of myristic acid (14:0) in the diet (expressed as \% of total dietary energy) was the strongest $(r=0.60, P<0.0001, n=80)$. All of these observations suggest that in hamsters, myristic acid although present in small quantities in the diet, is one of the saturated fatty acids most responsible for increasing the total plasma cholesterol concentration. However, contrary to previous studies in humans [14, $18,42,47]$ or animals $[10,15,35]$, it is interesting to note that the observed modifications in plasma total cholesterol only reflect variations in the HDL-cholesterol concentration (HDL-C) (Fig. 1). This effect is obviously noteworthy in the light of the known relationship between a higher HDL-C/LDL-C ratio and a lower incidence of CHD [8, 34]. Salter has already shown that in hamsters, increasing amounts of trimyristin in the diet (10 to $20 \%$ of total energy) increased the plasma HDL-C concentration [35]. The author suggested that the increase in the HDL-C concentration could implicate an inhibition of cholesteryl ester transfer protein activity (CETP) by myristic acid. However, the regulation of CETP activity by fatty acids is probably species-dependent since in man, saturated fatty acids (palmitic acid) increased the activity and the mass of CETP [22]. Consequently, the possible inhibitory effect of myristic acid on the activity or mass of CETP in hamsters still requires confirmation.

The recent identification of the scavenger receptor BI (SR-BI) as the first molecularly defined HDL receptor [1] represents an advance in the understanding of the regulation of HDL metabolism. The mass of hepatic SR-BI was significantly higher in animals fed the SA diet $(0.03 \%$ of total energy as myristic acid: $14: 0,17.9 \%$ of total energy as linoleic acid: $18: 2 n-6)$ than in animals fed the CO diet (4.2\% 14:0, 1.3\% 18:2n-6). Taken separately from the values obtained in the others groups, these results agree with those of Spady et al. [39] who have shown an increase in SR-BI (mass and m RNA) in hamsters fed a safflower diet (0\% 14:0, $24 \%$ $18: 2 n-6)$ compared to hamsters fed a coconut diet ( $5 \%$ 14:0, 0\% 18:2n-6). The authors explain this effect on SR-BI by the increase in the dietary linoleic acid proportion. In the present study, the hepatic mass of SR-BI in the LA group (0.5\% 14:0, $2.8 \%$ $18: 2 n-6)$ was two fold higher than that of the LCO group (2.3\% 14:0, $2.1 \%$ 18:2n-6) while the percentage of linoleic acid was 
similar. However, in these two groups, the percentage of myristic acid was divided by four. In the present study the regression between the SR-BI mass and the percentage of myristic acid was stronger than the regression between the SR-BI mass and the percentage of linoleic acid (Tab. III). The present results and those of Spady et al. [39] show that, in addition to linoleic acid, myristic acid plays a role in the regulation of the SR-BI expression. Hepatic lipase (HL) also plays an important role in HDL metabolism [34]. An "in vitro" study in rats by Hulsman et al. [16] demonstrated that, the activity of the HL more than doubles when unsaturated substrate is used instead of saturated substrate. A study in Man [6], has also shown an inverse correlation between the total saturated fat intake (or percentage of myristic or palmitic acids intake) and HL activity. Recently, Lambert et al. [23] have shown that HL (activity and interaction with SR-BI) promotes the selective uptake of high-density lipoprotein cholesteryl esters via SR-BI. All these data support the hypothesis that saturated fatty acids might act at two levels by decreasing HL activity and hepatic SR-BI content. The major consequence is an increase in HDL-C with a saturated diet and a decrease in HDL-C with an unsaturated diet. The observed decrease in HDL-C in hamsters fed SA and LA (the most unsaturated diets) is linked to the increase in SR-BI expression as observed by Spady et al. [39]. The LDL receptor also contributes to the regulation of cholesterolemia. Contrary to what is observed with SR-BI, the present data does not show evidence for a relationship between the level of myristic acid in the diet and the mass of the LDLr. However, a previous study [15] has shown that in hamsters the intake of a semi-purified diet containing $20 \%$ hydrogenated coconut oil: $(12: 0+14: 0)$ suppressed LDL receptor activity and decreased LDL receptor mRNA compared to a diet with $20 \%$ safflower oil. The differences between our results and those of Horton et al. [15] can be explained by the fact that in their study a higher level of saturated fatty acids was used (20\% versus $12.5 \%)$ and consequently a higher level of myristic acid.

The effects of myristic acid on bile acid biosynthesis were also evaluated by assaying the activities of the CYP7A1 and CYP27A1 enzymes. The variations of myristic acid $(0.03$ to $4.2 \%)$ in the different diets never induced modifications in the CYP7A1 and CYP27A1 activities. An increase in CYP7A1 activity in gerbils fed a cholesterol-free diet rich in linoleic acid (0\% 14:0) compared to a diet rich in myristic acid $(8 \%$ 14:0) was observed by Hajri et al. [11]. The differences with our results can be due either to species differences or to the fact that these authors used a coconut diet richer in myristic acid ( $8 \%$ versus $4.2 \%$ ). To our knowledge, there is very little information concerning an eventual regulatory effect of fatty acids on CYP27A1 activity. In the present study, different levels of myristic acid ( 0.03 to $4.2 \%$ ) do not alter the biosynthesis of bile acids or that of cholesterol since no differences in the HMGCoA activity of the different dietary groups was detected. These last data are similar to those found in previous studies [2, 38].

Hepatic triglyceride metabolism is modulated by changes in the type dietary fatty acids. All the diets (CO, MCO and LCO) containing coconut oil (rich in myristic and lauric acid) increased hepatic triglyceride concentrations compared with the MI, LA and SA diets. Nicolosi et al. [30] had already reported such an effect in gerbils when a coconut diet was compared to a safflower diet. These observations indicate a connection between the increase in the myristic acid level in the different diets and the increase in the hepatic triglyceride concentration. However, a comparison between the LCO diet (2.3\% 14:0; TG: $\left.12.9 \mathrm{mg} \cdot \mathrm{g}^{-1}\right)$ and the MI diet (2.8\% 14:0; TG: $9.8 \mathrm{mg} \cdot \mathrm{g}^{-1}$ ) does not show such a connection. A stronger regression between the hepatic triglyceride concentration and the percentage of lauric acid than between the hepatic triglyceride 
concentration and the percentage of myristic acid was observed (Tab. III ) suggesting that lauric acid is more efficient than myristic acid in hepatic triglyceride storage. The mechanism by which lauric acid modifies hepatic lipid metabolism is presently unclear. Previous metabolic data have demonstrated that medium chain fatty acids (lauric acid) are preferentially oxidized via the $\beta$ oxidation pathway and long chain fatty acids are preferentially incorporated into the triglyceride molecule [24, 45]. A recent study [33] has proposed that the elongation of lauric acid after partial oxidation could explain hepatic TG accumulation in the liver of calves fed a coconut diet. An eventual inhibitory effect of lauric acid (or stimulating effect of polyunsaturated fatty acids) on hepatic triglyceride secretion via the VLDL pathway could also be responsible for TG accumulation [30].

In conclusion, this study shows that increasing amounts of dietary myristic acid (0.03 to $4.2 \%$ ) slightly modify cholesterol metabolism and increase only the HDL-C. The data obtained also show that dietary fat (particularly myristic and linoleic acids) are able to regulate SR-BI expression. Further work will be required to understand the mechanism and the transcription factors (SREBPs, PPARs, etc.) involved in this regulation.

\section{ACKNOWLEDGEMENTS}

The authors thank Dr. M. Parquet for scientific discussion, C. Verneau for technical assistance and N. Samson for animal care.

\section{REFERENCES}

[1] Acton S., Rigotti A., Landschulz K.R., Xu S., Hobbs H., Krieger M., Identification of scavenger receptor SR-B1 as high-density lipoprotein receptor, Science 271 (1996) 518-520.

[2] Bennett A.J., Billett M.A., Salter A.M., Mangiapane E.H., Bruce J.S., Anderton K.L., Marenah C.B., Lawson N., White D.A., Modulation of hepatic apolipoprotein B, 3 hydroxy-
3-methylglutaryl-coA reductase and low density lipoprotein receptor m RNA and plasma lipoprotein concentrations by defined dietary fats, Biochem. J. 311 (1995) 167-173.

[3] Boutin J., Myristoylation, Cell Signal. 9 (1997) 15-35.

[4] Cheema S.K., Cikaluk D., Agellon L.B., Dietary fats modulate the regulatory potential of dietary cholesterol on cholesterol $7 \alpha$-hydroxylase gene expression, J. Lipid Res. 38 (1997) 315-328.

[5] Combettes-Souverain M., Milliat F., Sérougne C., Férézou J., Lutton C., SR-BI et métabolisme du cholestérol, M.S. Méd. Sci. 15 (1999) 1252-1258.

[6] Dreon D.M., Fernstrom H.A., Canpos H., Blanche P., Williams P.T., Krauss R.M., Change in dietary saturated fat intake is correlated with change in mass of large low-density-lipoprotein particles in men, Am. J. Clin. Nutr. 67 (1998) 828-836.

[7] Einarsson K., Angelin B., Ewerth S., Nilsell K., Björkhem I., Bile acid synthesis in man: assay of hepatic microsomal cholesterol $7 \alpha$-hydroxylase activity by isotope dilution-mass spectrometry, J. Lipid Res. 27 (1986) 82-88.

[8] Gordon T., The diet-heart idea: outline of a history, Am. J. Epidemiol. 127 (1988) 220-225.

[9] Grundy S.M., What is the desirable ratio of saturated, polyunsaturated and monounsaturated fatty acid in the diet, Am. J. Clin. Nutr. 66 (1997) 988S-990S.

[10] Hajri T., Khosla P., Pronczuk A., Hayes K.C., Myristic acid-rich fat raises plasma LDL by stimulating LDL production without affecting fractional clearance in gerbils fed a cholesterolfree diet, J. Nutr. 128 (1998) 477-484.

[11] Hajri T., Pronzuk A., Hayes K.C., Linoleic acid rich diet increases hepatic taurine and cholesterol 7 alpha hydroxylase activity in conjunction with altered bile acid composition and conjugation in gerbils, J. Nutr. Biochem. 9 (1998) 249-257.

[12] Hayes K.C., Pronczuk A., Lindsey S., Diersen-Schade D., Dietary saturated fatty acids C12:0, C14:0, C16:0 differ in their impact on plasma cholesterol and lipoproteins in non human primates, Am. J. Clin. Nutr. 53 (1991) 491-498.

[13] Hayes K.C., Khosla P., Dietary fatty acid thresholds and cholesterolemia, FASEB J. 6 (1992) 2600-2607

[14] Hegsted D.M., Mc Gandy R.B., Myers M.L., Stare F.J., Quantitative effects of dietary fat on serum cholesterol in man, Am. J. Clin. Nutr. 17 (1965) 281-295.

[15] Horton J.D., Cuthbert J.A., Spady D.K., Dietary fatty acids regulate hepatic low Density Lipoprotein (LDL) transport by altering LDL Receptor protein and m RNA levels, J. Clin. Invest. 92 (1993) 743-749. 
[16] Hulsman W.C., Oerlemans M.C., Jansen H., Activity of heparin-releasable liver lipase. Dependence on the degree of saturation of the fatty acids in the acyl-glycerol substrates, Biochim. Biophys. Acta 618 (1980) 364-369.

[17] Jensen R.G., The lipids in human milk, J. Lipid Res. 35 (1996) 53-92.

[18] Keys A., Parlin R.W., Serum cholesterol response to changes in dietary lipids, Am. J. Clin. Nutr. 19 (1966) 175-181.

[19] Kovanen P.T., Brown M.J., Goldstein J.L., Increased binding of low density lipoprotein to liver membranes from rats treated with 17 $\alpha$-ethinyl estradiol, J. Biol. Chem. 254 (1979) 11367-11373.

[20] Kris-Etherton P.M., Dietschy J., Design criteria for studies examining individual fatty acids effects on cardiovascular disease risk factors: human and animal studies, Am. J. Clin. Nutr. 65S (1997) 159S-166S.

[21] Kris-Etherton P.M., Yu S., Individual fatty acid effects on plasma lipids and lipoproteins: human studies, Am. J. Clin. Nutr. 65 (1997) 1628S-1644S

[22] Lagrost L., Mensink R.P., Guyard-Dangremont V., Temme E.H.M., Desrumaux C., Athias A., Hornstra G., Gambert P., Variations in serum cholesteryl ester transfer and phospholipid transfer activities in healthy women and men consuming diets enriched in Lauric, Palmitic or oleic acid, Atherosclerosis 142 (1999) 395-402.

[23] Lambert G., Chase M.B., Dugi K., Bensadoun A., Brewer H.B., Santamarina-Fojo S., Hepatic lipase promotes the selective uptake of high density lipoprotein-cholesteryl esters via the scavenger receptor B1, J. Lipid Res. 40 (1999) 1294-1303.

[24] Leyton P., Drury P.J., Crawford M.A., In vivo incorporation of labeled fatty acids in rat liver lipids after oral administration, Lipids 8 (1987) 553-558.

[25] Lindsey S., Benattar J., Pronczuk A., Hayes K.C., Dietary palmitic acid (16:0) enhances high density lipoprotein cholesterol and low density lipoprotein receptor mRNA abundance in hamsters, Proc. Soc. Exp. Biol. Med. 195 (1990) 261-269.

[26] Lowry O.H., Rosebrough N.J., Farr A.L., Randall R.J., Protein measurement with Folin phenol reagent, J. Biol. Chem. 192 (1951) 265-275.

[27] Mc Donald B.E., Gerrard J.M., Brucce V.M., Cormer E.J., Comparison of the effect of canola oil and sunflower oil on plasma lipids and lipoproteins and in vivo thromboxane A2 and prostacyclin production in healthy young men, Am. J. Clin. Nutr. 50 (1989) 1382-1388.

[28] Mattson F.H., Grundy M.H., Comparison of effects of dietary saturated, monounsaturated and polyunsaturated on plasma lipids and lipoproteins in man, J. Lipid Res. 26 (1985) 194-202.
[29] Milliat F., Grippois D., Blouquit M.F., Ferezou J., Serougne C., Fidge N.H., Lutton C., Short and long-term effects of steptozotocin on dietary cholesterol absorption, plasma lipoproteins and liver lipoprotein receptors in rico rats, Exp. Clin. Endocrinol. Diabetes 108 (2000) 436-446.

[30] Nicolosi R.J., Herrera M.G., El Lozy M., Hayes K.C., Effects of dietary fat on hepatic of ${ }^{14} \mathrm{C}$-oleic acid and very low density lipoprotein triglyceride in the gerbil, J. Nutr. 9 (1976) 1279-1285.

[31] Nicolosi R.J., Dietary fat saturation effects on low-density lipoprotein concentrations and metabolism in various animal models, Am. J. Clin. Nutr. 65 (1997) 1617S-1627S.

[32] Philipp B.W., Shapiro D.J., Improved method for the assay and activation of 3-hydroxy3-methylglutaryl CoA reductase, J. Lipid Res. 20 (1979) 588-593.

[33] Piot C., Hocquette J.F., Veerkamp J.H., Durand D., Bauchart D., Effects of dietary coconut oil on fatty acid oxydation capacity of the liver, the heart and skeletal muscles in the preruminant calf, Br. J. Nutr. 82 (1999) 299-308.

[34] Rader J.D., Maugeais C., Genes influencing HDL metabolism: new perspectives and implications for atherosclerosis prevention, Mol. Med. Today 6 (2000) 170-175.

[35] Salter A.M., Mangiapane E.H., Bennet A.J., Bruce J.S., Billet M.A., Anderton K.L., Marenah C.B., Lawson N., White D.A., The effect of different dietary fatty acids on lipoprotein metabolism: concentration dependent effects of diet enriched in oleic, myristic, palmitic and stearic acids, Br. J. Nutr. 79 (1998) 195-202.

[36] Schneider W.J., Beisiegel U., Goldstein J.L., Brown M.S., Purification of the low density lipoprotein receptor, on acidic glycoprotein of 164000 molecular weight, J. Biol. Chem. 257 (1982) 2664-2673.

[37] Spady D.K., Dietschy J.M., Sterol synthesis in vivo in 18 tissues of the squirrel monkey, guinea pig, rabbit, hamster and rat, J. Lipid Res. 24 (1983) 303-315.

[38] Spady D.K., Dietschy J.M., Interaction of dietary cholesterol and triglycerides in the regulation of hepatic low-density lipoprotein transport in the hamster, J. Clin. Invest. 81 (1988) 300-309.

[39] Spady D.K., Kearney D.M., Hobbs H.H., Polyunsaturated fatty acids up-regulate hepatic scavenger receptor B1 (SR-B1) expression and HDL cholesteryl ester uptake in the Hamster, J. Lipid Res. 40 (1999) 1384-1394.

[40] Souidi M., Parquet M., Lutton C., Improved assay of hepatic microsomal cholesterol $7 \alpha$-hydroxylase activity by use of hydroxyl$\beta$-cyclodextrin and an NADPH regenerating system, Clin. Chim. Acta 269 (1998) 201-217.

[41] Souidi M., Parquet M., Férézou J., Lutton C., Modulation of cholesterol $7 \alpha$ hydroxylase and sterol 27-hydroxylase activities by steroids and physiological conditions in hamster, Life Sci. 64 (1999) 1585-1593. 
[42] Temme E.H.M., Mensink R.P., Hornstra G., Effects of medium chain fatty acids (MCFA), myristic acid, and oleic acid on serum lipoprotein in healthy subjects, J. Lipid Res. 38 (1997) 1746-1754.

[43] Terpstra A.H.M., Woodward C.J.H., SanchezMuniz F.J., Improved techniques for the separation of serum lipoproteins by density gradient ultracentrifugation. Visualization by pertaining and rapid separation of serum lipoproteins from small volumes of serum, Anal. Biochem. 111 (1981) 149-157.

[44] Vlahcevic Z.R., Jairah S.K., Heuman D.M., Stravitz R.T., Hylemon P.B., Avadhani N.G., Pandak W.M., Transcriptional regulation of hep- atic sterol 27-hydroxylase by bile acids, Am. J. Physiol. 270 (1996) G646-G652.

[45] Wang S., Koo I.S., Plasma clearance and hepatic utilization of stearic, myristic and linoleic acids introduced via chylomicrons in rats, Lipids 28 (1993) 697-703.

[46] Woolett L.A., Spady D.K., Dietschy J.M., Regulatory effects of the saturated fatty acids 6:0 trough 18:0 on hepatic low density lipoprotein receptor activity in the hamster, J. Clin. Invest. 89 (1992) 1133-1141.

[47] Zock P., De Vries J., Katan M., Impact of myristic acid versus palmitic acid on serum lipid and lipoprotein levels in healthy women and men, Arterioscler. Thromb. 14 (1994) 567-575. 